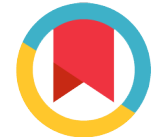

Check for updates

\section{Comparison of DNA Damage and Homocysteine Content in Blood of Thyroid Carcinoma Patients and Control Subjects in Punjab, Pakistan}

\author{
Muhammad Usman1,2, Muhammad Ibrahim Rajoka2, Asma Haque², \\ Shumaila Bakhtiar², Luqman Khan ${ }^{3, *}$, Zubair Ibrahim4, Farid ul Haq², \\ Shah Fahad³, Qazi Adnan Ahmad³
}

\author{
1Department of Bioinformatics \& Computational Biology, Virtual University of Pakistan, \\ Lahore, Pakistan \\ 2Department of Bioinformatics and Biotechnology, Government College University, \\ Faisalabad, Pakistan \\ 3Department of Zoology, Government College University, Faisalabad, Pakistan \\ ${ }^{4}$ College of Pharmacy, Government College University, Faisalabad, Pakistan
}

For correspondence:

luqman.zoology@gmail.com

Competing interests: The authors declare that no competing interests exist.

Received: 13 December 2017

Accepted: 11 January 2018

Published: 25 January 2018

Copyright The Author(s) 2018. This article is published with open access by BioMedPress

This article is distributed under the terms of the Creative Commons Attribution License (CC-BY 4.0) which permits any use, distribution, and reproduction in any medium, provided the original author(s) and the source are credited.

\begin{abstract}
Background: Thyroid cancers are common endocrine tumors with diverse medical and histological structures. During development/progression from normal to neoplastic cell, there is a gradual increase in the function/activity of proto-oncogenes, transcription factors and metastasis elements. The main objective of this study is to evaluate per-oxidation of lipid content, total oxidative stress, and the profile of homocysteine (and DNA damage) in the erythrocytes of thyroid carcinoma patients as compared with those of control subjects. Methods: All risk variables and biochemical analyses were quantitatively determined using standard methods. Results: A noteworthy increase in malondialdehyde, globulin, and DNA damage in thyroid carcinoma patients were repeatedly observed. In contrast, healthy individuals showed an increased level of HDL-C and total anti-oxidant response. Conclusion: It is suggested that these parameters have a pivotal role in the diagnostic process of determining thyroid carcinoma patients. Oxidized products of macromolecules in the blood of such patients impart major function in causing thyroid carcinoma disease.
\end{abstract}




\section{Keywords}

Antioxidants, DNA damage, Homocysteine, Oxidative stress, Thyroid carcinoma disease, TOS

\section{Introduction}

Among all malignant cancers, thyroid carcinoma is being witnessed in increasing cases in European countries, USA and Canada (Siti et al., 2015; Mancini et al., 2016; Valko et al., 2007). It is more aggressive and common in the 30-60 year age group. Human body cells consume oxygen to generate energy but oxygen is inherently fatal for their survival (Siti et al., 2015) as it causes oxidative stress (OS), which is due to the unbalanced level of generation of pro-oxidant molecules and production of anti-oxidant defenses the body synthesizes (Mancini et al., 2016). Reactive oxygen species (ROS) and reactive nitrogen species (RNS) are considered as both toxic and beneficial species (Valko et al., 2007). If in high concentration, they react with DNA, proteins and lipids, and can chemically alter their function (Le Bras et al., 2005). In cancer cells, oxidative stress has been linked to the regulation of numerous cellular processes including DNA damage, cellular adhesion and migration, proliferation, and the regulation of cell survival or death (Mancini et al., 2016). Earlier studies on the role of ROS and RNS in tumor development revealed that they both act as DNA-damaging agents by increasing the mutation rate within cells alarmingly and enhancing oncogenic transformation (Jackson and Loeb, 2001).

ROS and RNS have the inherent potential to enhance specific intracellular events during communication of messages between cellular parts. As well, they take part in the development of tumors and their spreading to other parts of the body by regulating related processes including proliferation, death and mortality. These effects are due to hydroxyl and peroxynitrite radicals which possess the capacity to act in a non-specific and destructive manner. They can specifically activate certain intracellular signaling cascades and, thus, contribute to tumor development and metastasis through the regulation of cellular phenotypes as mentioned above (Karbownik and Lewinski, 2003). According to the suggestions of growing evidences, the production of ROS is highly controlled in many cases, acting on specific downstream targets (Finkel, 2003).

Oxidative stress is very common in thyroid tissues while consuming hydrogen peroxide $\left(\mathrm{H}_{2} \mathrm{O}_{2}\right)$ for thyroxin synthesis. Inflammation and oxidative stress are closely linked processes (Mancini et al., 2016; Fuejita, 2002). OS causes hormonal derangement in a reciprocal way (Mancini et al., 2016). OS is also linked with hyperthyroidism and hypothyroidism in all animals. However, very little is known about the oxidant/antioxidant balance in thyroid cancer (Sadani, 
1996). Papillary thyroid cancer comprises of $57-89 \%$ of all thyroid malignancies as reported by previous reports from this region (Abdulmughni et al., 2004; Mulaudzi et al., 2001). In this region of the world, the ratio of female to male is 2.5 to $4: 1$, and is comparable to international findings. Yet, there is no study to date evaluating the effects of complete resection of the thyroid tissue on this balance.

Serum malondialdehyde (MDA) is frequently utilized as an indicator for oxidative damage in tissues and cells (Finkel, 2003; Erel, 2005). In cells, the peroxide level is determined by the balance between the production and elimination of lipid peroxides. The disturbance in this balance can be caused by decrease in cellular defenses and/or by the remarkable increase in peroxidative reactions (Karbownik and Lewinski, 2003).

Thyroid glands are surgically removed as an initial therapy for the treatment. The purpose of this surgery is to eliminate the tissues which have been affected by the tumor. lodine-131 is given post-operatively to destroy any remnants left after surgery. It may be effective in doing the whole body scan (WBS) for the persistence of cancer and for decreasing the long-term effects of recurrent carcinoma.

Thus, in order to further delineate the role of oxidant/antioxidant balance in the thyroid cancer, the aim of this study was to analyze the lipid peroxidation outcome (malondialdehyde) in blood samples of thyroid cancer patients after the thyroidectomy operation, and compared with healthy controls.

\section{Materials-Methods}

\section{Chemicals}

All chemicals were purchased from Sigma-Aldrich (St. Louis, MO, USA). All kits were procured from the local suppliers representing the multi-national chemical companies, as indicated in the text.

\section{Subjects}

Thirty subjects diagnosed with thyroid carcinoma were included in this study and advised to undergo thyroidectomy at the Punjab Institute of Nuclear Medicines (PINUM) in Faisalabad, Pakistan. Thirty healthy subjects (age-, genetic background-, and sex-matched) related to the patients were considered as control subjects. Informed consent was obtained from all the subjects in this study. This work was performed according to standard ethical guidelines of local authorities.

\section{Sample Collection}


A total of 60 blood samples were collected aseptically from patients $(n=30)$ and controls $(n=30)$ into $4 \mathrm{ml}$ vacutainers with and without K2-EDTA from the antecubital vein of each participant diagnosed for thyroid cancer. Blood samples were processed for plasma and serum. Analysis of all samples was performed in triplicate for different variables in GCUF laboratory. A physician regularly conducted the physical examination of all participants on this study. Blood pressure of all participants was measured by using sphygmomanometer and readings were recorded as systolic and diastolic pressure. The range of body mass index (BMI) was $24.83 \pm 0.53$ for control subjects; thyroid carcinoma patients had BMI range of $26.14 \pm 2.53$, which was not significantly different.

\section{Serum Biochemistry}

Hemoglobin concentration $(\mathrm{Hb} ; \mathrm{g} / \mathrm{dL}$ ) was determined by cyanmethemoglobin method. The absorbance was measured at $540 \mathrm{~nm}$ on a spectrophotometer (BENJAMIN, 1978) Commercially available Fluitest Glu Biocon kit (Lot\# H265) was used for testing glucose levels via a spectrophotometer (Screen Master \#35510). Glycosylated hemoglobin (HB; HbA1c; \%) was determined using the boronate affinity chromatography for Glycosal ${ }^{T M}$ test to assess the quantity of glycosylated hemoglobin fragments from that of non-glycosylated fragments. The \% HbA1c for the samples was obtained from an algorithm measuring both fragments.

The erythrocyte sedimentation rate (ESR; $\mathrm{mm} / \mathrm{h}$ ) was determined by Westergren method (Benjamin, 1978). Total homocysteine (tHcy) was determined by the application of homocysteine microtiter plate assay in sera of normal subjects and of patients. Total oxidant status (TOS; $\mu \mathrm{mol} \mathrm{H}_{2} \mathrm{O}_{2}$ equiv/L) was measured using an automated colorimetric method (Karbownik and Lewinski, 2003; Finkel, 2003). Total antioxidant response (TAR) or total antioxidant status (TAS; mmol trolox Equiv./L) was determined using an automated calorimetric method (Erel, 2005). Malondialdehyde (MDA; $\mu \mathrm{mol} / \mathrm{L})$ was determined using laboratory kit and spectrophotometer (UV/VIS) (Fujita, 2002).

DNA damage was measured using 8-hydroxy-deoxy guanosine enzyme immunoassay (EIA) kit as described earlier (Jackson and Loeb, 2001). Triiodothyronine (T3; ng/ml) was determined using T3 EIA kit (BioCheck Inc., South San Francisco, CA, USA; cat. \# BC-1005). For the measurement of total thyroxin (T4) concentration, EIA kit (BioCheck) was used. Total thyroid stimulating hormone (TSH) was assessed using EIA kit (BioCheck) as previously done (Fujita, 2002). Estrogen (estradiol, E2) was determined by using EIA kit as well (Sadani, 1996). Aspartate aminotransferase (AST) and alanine aminotransaminase (ALT) were determined by Reitman-Frankel colorimetric method by using a commercial kit (Crescent Diagnostics; cat. \#CZ902C). Triiodothyronine was quantitatively determined by the $\mathrm{T}_{3}$ EIA kit (BioCheck). The overall $\mathrm{T}_{4}, \mathrm{TSH}$ and E2 concentrations were quantified, as aforementioned, by their respective EIA kits (BioCheck). 


\section{Statistical Analysis}

From the data, mean \pm SD were calculated. To calculate the differences between normal (control subjects) and thyroid carcinoma patients, data were analyzed by three-way analysis of variance (Steel, 1997). In case of significant differences, Duncan Multiple Range Test (DMRT) was applied (Duncan, 1955). GraphPad Prism Software (San Diego, CA, USA) was used to calculate statistical significance of the results.

\section{Results}

Mean \pm SD of the age (in years) of the patients (39.9 \pm 4.52$)$ and control subjects $(38.36 \pm 5.4)$ were not significantly different. The median age at the time of diagnosis was 45 to 50 years.

\section{Anthropometry}

Analysis of various anthropometric parameters of controls and thyroid cancer patients was done. One-way analysis of variance (ANOVA) calculation suggested that $\mathrm{BMI}$ was significantly higher $(\mathrm{P}<0.0008)$ in patients compared to that of normal subjects. Hemoglobin was not significantly $(P=0.3891)$ different between diseased and normal subjects, i.e. Hb levels were within normal range for both. However, in the case of ESR, it was significantly higher $(P=0.0188)$ in diseased cases than in normal subjects (Table 1).

\section{Serum Biochemical Parameters}

All risk factors of thyroid carcinoma were significantly higher in diseased subjects. In contrast, glycosylated Hb was non-significantly $(p=0.0914)$ higher in patients. Diseased subjects had relatively higher values of ALT, AST and TSH $(p<0.0001)$ than those of normal subjects. T4 and T3 were considered not significantly different in subjects versus controls $(p=0.426$ and $p=0.3280$, respectively, for T4 and T3). Diseased subjects had showed significantly higher values of estradiol, homocysteine and TOS $(p<0.0001)$ than those of their respective normal subjects.

Diseased subjects had a significantly higher value of MDA $(p=0.0001)$ than those of control subjects. DNA damage was significantly $(p<0.0001)$ higher in diseased than normal subjects. Moreover, TAR was considered significantly $(p<0.0001)$ higher in healthy individuals as compared to that for diseased subjects. 


\section{Table 1. Clinical and laboratory parameters of patients and control subjects (Mean+SE)}

\begin{tabular}{|c|c|c|c|}
\hline Parameters & Patients $(n=30)$ & Controls $(n=30)$ & P-value \\
\hline Age, years & $39.9 \pm 4.52$ & $38.36 \pm 5.4$ & 0.2359 \\
\hline BMI (kg/m2) & $28.08 \pm 1.07$ & $21.1 \pm 1.39$ & $<0.0001$ \\
\hline Hemoglobin $(\mathrm{Hb} ; \mathrm{g} / \mathrm{dL})$ & $12.75 \pm 0.5$ & $13.2 \pm 0.23$ & $<0.0001$ \\
\hline $\operatorname{ESR}(\mathrm{mm} / \mathrm{h})$ & $26.49 \pm 3.64$ & $16.29 \pm 2.6$ & $<0.0001$ \\
\hline ALT ( U/L) & $41.88 \pm 10.39$ & $21.52 \pm 2.65$ & $<0.0001$ \\
\hline AST (U/L) & $33.57 \pm 5.49$ & $14.55 \pm 1.23$ & $<0.0001$ \\
\hline $\mathrm{TSH}(\mu \mathrm{U} / \mathrm{mL})$ & $7.64 \pm 5.37$ & $3.85 \pm 1.46$ & $<0.0001$ \\
\hline Free T3 (ng/mL) & $3.48 \pm 0.42$ & $3.55 \pm 1$ & 0.426 \\
\hline Free T4 $(\mu \mathrm{g} / \mathrm{dL})$ & $18.58 \pm 3.7$ & $17.8 \pm 5.25$ & 0.3280 \\
\hline Estradiol (E2; pg/ mL) & $345.8 \pm 24.3$ & $145.97 \pm 13.79$ & $<0.0001$ \\
\hline Hcy (mol/L) & $94.17 \pm 6.28$ & $10.75 \pm 0.4$ & $<0.0001$ \\
\hline TOS (mol H2O2 Equiv. /L) & $96.385 \pm 4.38$ & $10.49 \pm 0.37$ & $<0.0001$ \\
\hline MDA (mol/L) & $2.87 \pm 0.92$ & $1.33 \pm 0.43$ & $<0.0001$ \\
\hline TAR (mmol/ Trolox) & $2.23 \pm 0.56$ & $1.48 \pm 0.03$ & $<0.0001$ \\
\hline DNA damage (m) & $46.62 \pm 6.22$ & $6.0 \pm 1.1$ & $<0.0001$ \\
\hline
\end{tabular}

The Pearson correlation of homocysteine, TOS and DNA damage with anthropometric measurements, biochemicals, lipid profile, LFTs, serum hormones and health biomarkers have been evaluated for control subjects and diseased subjects. Serum homocysteine showed a negative correlation with $\mathrm{Hb}$, albumin, cholesterol, triglycerides, HDL, LDLs, TSH, and estrogen in diseased subjects. A positive but non-significantly different relationship of homocysteine was established with BMI, RBS, HbA1C, T3, T4, TOS, TAR, MDA and DNA damage. It was related significantly with ESR, ALT, AST, TOS and DNA damage but negatively with TAR. The Pearson correlation of DNA damage with anthropometrics, biochemicals, lipid profile, LFTs, serum hormones and health biomarkers of patients are presented in Table 3. DNA damage showed a negative correlation with ESR, HBA1C, cholesterol, TGs, LDL, T3, T4 and E2. A positive relationship of DNA damage was established with $\mathrm{BMI}$, hemoglobin, random blood sugar, albumin, total proteins, ALT, AST, TSH, TOS, homocysteine, MDA and TAR. 
The Pearson correlation of TOS with anthropometrics, biochemicals, lipid profile, LFTs, serum hormones and health biomarkers in healthy control subjects are also shown. TOS showed a negative correlation with hemoglobin, HBA1C, triglycerides, HDL and T3. A positive relationship of TOS was established with $B M I, E S R$, random blood sugars, total proteins, albumin, cholesterol, LDL, ALT, AST, TSH, T4, estrogen, homocysteine, MDA and DNA damage. Overall, statistical analyses showed a positive relationship of thyroid carcinoma with DNA damage, oxidative stress, MDA and homocysteine level; indeed, these all are potential markers of thyroid carcinome (Tables $2 \& 3$ ).

\section{Table 2. Correlation of oxidative stress, DNA damage and homocysteine with other attributes in control subjects}

\begin{tabular}{|c|c|c|c|}
\hline & Homocysteine & $\begin{array}{l}\text { Total Oxidant Status } \\
\text { (TOS) }\end{array}$ & DNA damage \\
\hline \multirow{2}{*}{$\begin{array}{l}\text { Homocysteine } \\
\text { (mol/L) }\end{array}$} & 1.000 & 0.498 & 0.535 \\
\hline & & 0.313 & 0.274 \\
\hline \multirow{2}{*}{$\begin{array}{c}\text { TOS (mol H2O2 } \\
\text { equiv./L) }\end{array}$} & 0.498 & 1.000 & 0.500 \\
\hline & 0.313 & & 0.312 \\
\hline \multirow{2}{*}{ DNA damage (m) } & 0.535 & 0.500 & 1.000 \\
\hline & 0.274 & 0.312 & \\
\hline \multirow{2}{*}{ TAR (mmol/Trolox) } & -0.252 & -0.261 & -0.250 \\
\hline & 0.635 & 0.712 & 0.633 \\
\hline \multirow{2}{*}{ MDA (mol/L) } & -0.002 & -0.049 & 0.434 \\
\hline & 0.997 & 0.927 & 0.259 \\
\hline \multirow{2}{*}{ Age (years) } & -0.460 & -0.487 & 0.495 \\
\hline & 0.359 & 0.328 & 0.318 \\
\hline \multirow{2}{*}{ BMI (kg/m2) } & -0.635 & -0.673 & 0.294 \\
\hline & 0.175 & 0.143 & 0.572 \\
\hline \multirow{2}{*}{$\begin{array}{l}\text { Hemoglobin (Hb; } \\
\text { g/dL) }\end{array}$} & -0.331 & -0.460 & -0.005 \\
\hline & 0.071 & 0.359 & 0.993 \\
\hline \multirow{2}{*}{$\operatorname{ESR}(\mathrm{mm} / \mathrm{h})$} & 0.713 & 0.686 & 0.772 \\
\hline & 0.112 & 0.132 & 0.145 \\
\hline \multirow{2}{*}{$\begin{array}{l}\text { Glycosylated Hb } \\
\text { (HBA1c; \%) }\end{array}$} & 0.131 & 0.096 & 0.095 \\
\hline & 0.804 & 0.856 & 0.857 \\
\hline Aspartate & 0.591 & 0.561 & 0.496 \\
\hline
\end{tabular}




\begin{tabular}{|c|c|c|c|}
\hline $\begin{array}{c}\text { Aminotransferase } \\
\text { (AST; U/L) }\end{array}$ & 0.217 & 0.247 & 0.315 \\
\hline $\begin{array}{c}\text { Alanine } \\
\text { Aminotransferase } \\
\text { (ALT; U/L) }\end{array}$ & -0.382 & -0.421 & 0.574 \\
\hline TSH & 0.454 & 0.406 & 0.233 \\
\hline & 0.415 & 0.384 & 0.385 \\
\hline FT3 & 0.258 & 0.452 & 0.453 \\
\hline & 0.622 & 0.229 & 0.440 \\
\hline FT4 & 0.499 & 0.663 & 0.645 \\
\hline & 0.311 & 0.520 & 0.520 \\
\hline
\end{tabular}

Upper values indicate Pearson's correlation coefficient; lower values indicate level of significance at $5 \%$ probability. ${ }^{\star}=$ significant $(P<0.05) ;{ }^{\star \star}=$ highly significant $(P<0.01)$.

Table 3. Correlation of oxidative stress, DNA damage and homocysteine with other attributes in patients

\begin{tabular}{|c|c|c|c|}
\hline & Homocysteine & $\begin{array}{l}\text { Total Oxidant Status } \\
\text { (TOS) }\end{array}$ & DNA damage \\
\hline \multirow{2}{*}{ Homocysteine (mol/L) } & 1.000 & 0.900 & 0.899 \\
\hline & & 0.048 & 0.048 \\
\hline \multirow{2}{*}{$\begin{array}{c}\text { Total Oxidant Status } \\
\text { (TOS; mol H2O2 } \\
\text { equiv./L) }\end{array}$} & $0.996^{\star \star}$ & 1.000 & 0.890 \\
\hline & 0.001 & & 0.049 \\
\hline \multirow{2}{*}{ DNA damage $(\mathrm{m})$} & 0.899 & 0.248 & 1.000 \\
\hline & 0.048 & 0.636 & \\
\hline \multirow{2}{*}{$\begin{array}{c}\text { Total Antioxidant } \\
\text { Response (TAR; mmol/ } \\
\text { Trolox) }\end{array}$} & $0.996^{\star \star}$ & -0.051 & 0.803 \\
\hline & 0.001 & 0.923 & 0.054 \\
\hline \multirow{2}{*}{$\begin{array}{l}\text { Malondialdehyde } \\
\text { (MDA; mol/L) }\end{array}$} & 0.837 & 0.845 & $0.914^{*}$ \\
\hline & 0.045 & 0.046 & 0.011 \\
\hline \multirow{2}{*}{ Age (years) } & $0.969 * \star$ & $0.828^{\star}$ & $0.846^{\star}$ \\
\hline & 0.001 & 0.035 & 0.034 \\
\hline \multirow{2}{*}{$\begin{array}{l}\text { Body Mass Index } \\
\text { (BMI; kg/m2) }\end{array}$} & $0.872^{\star}$ & $0.858^{\star}$ & $0.870 *$ \\
\hline & 0.025 & 0.023 & 0.024 \\
\hline \multirow{2}{*}{$\begin{array}{l}\text { Hemoglobin (Hb; g/ } \\
\text { dL) }\end{array}$} & $0.926^{\star \star}$ & 0.850 & $0.865^{\star}$ \\
\hline & 0.008 & 0.047 & 0.026 \\
\hline
\end{tabular}




\section{Biomedical}

Research \& Therapy
ISSN: $2198-4093$ www.bmrat.org

\begin{tabular}{|c|c|c|c|}
\hline \multirow{2}{*}{$\begin{array}{c}\text { Erythrocyte } \\
\text { Sedimentation Rate } \\
\text { (ESR; } \mathrm{mm} / \mathrm{hr})\end{array}$} & 0.852 & $0.872^{\star}$ & $0.875^{\star}$ \\
\hline & 0.020 & 0.023 & 0.022 \\
\hline \multirow{2}{*}{$\begin{array}{l}\text { Glycosylated Hb } \\
\text { (HBA1c; \%) }\end{array}$} & $0.877^{\star}$ & $0.843^{\star}$ & $0.965^{\star *}$ \\
\hline & 0.049 & 0.039 & 0.002 \\
\hline \multirow{2}{*}{$\begin{array}{c}\text { Aspartate } \\
\text { Aminotransferase } \\
\text { (AST; U/L) }\end{array}$} & $0.925^{\star \star}$ & 0.469 & 0.684 \\
\hline & 0.008 & 0.348 & 0.134 \\
\hline \multirow{2}{*}{$\begin{array}{c}\text { Alanine } \\
\text { Aminotransferase } \\
\text { (ALT; U/L) }\end{array}$} & $0.836^{\star}$ & 0.637 & 0.542 \\
\hline & 0.038 & 0.174 & 0.266 \\
\hline \multirow{2}{*}{ TSH } & $0.988 * *$ & 0.902 & $0.880 *$ \\
\hline & 0.000 & 0.011 & 0.021 \\
\hline \multirow{2}{*}{ FT3 } & 0.823 & $0.894^{\star}$ & 0.554 \\
\hline & 0.033 & 0.016 & 0.254 \\
\hline \multirow{2}{*}{ FT4 } & 0.907 & $0.915^{\star}$ & 0.954 \\
\hline & 0.423 & 0.011 & 0.001 \\
\hline
\end{tabular}

Upper values indicate Pearson's correlation coefficient; lower values indicate level of significance at $5 \%$ probability. ${ }^{*}=$ significant $(P<0.05) ;{ }^{\star \star}=$ highly significant $(P<0.01)$.

\section{Discussion}

The demographic characteristics of thyroid cancer patients are comparable with those of European countries. Even so, the clinical reports are quite diverse and more aggressive. Age and sex were not correlated with aggressiveness of disease. Of the differentiating thyroid cancers, PTC (papillary thyroid cancer) was mostly observed (76.66\%), whereas FTC (follicular thyroid cancer) was less frequently observed (13.33\%) as was Hurthle cell cancer (10\% of total patients).

We observed very few children and adolescents affected with PTC and FTC (2 patients in our study); regarding age onset the chances of PTC and FTC increased in adults. The median age of diagnosis (based on our criteria) in this study was 45 to 50 years. We observed a higher ratio of thyroid carcinoma in women as compared to men ( 5 women for every 2 men).

Our study demonstrated that BMI was significantly high in thyroid carcinoma patients compared to controls $(p=0.0008)$. In such patients, thyroid glands were removed surgically and patients were given thyroxin (orally) so that their body metabolism would function like normal individuals (Kitahara et al., 2011). Kitahara et al. suggested in their work that for both men and women, BMI was 
found to be linked with thyroid carcinoma risk. Their findings give a strong indication that obesity is an independent risk factor for thyroid cancer.

In our study, hemoglobin was found to be within normal range in thyroid carcinoma patients. It was not significantly different in cancer patients versus healthy controls. The same was true for ESR; it was not significantly different between cancer patients and control subjects. However, ESR was slight above normal range in patients who were Hepatitis C Virus (HCV) positive.

ALT and AST are linked with liver function; their concentrations can be used to detect hepato-cellular injury and reflect the status of the liver. In the present study, ALT and AST levels were higher in several cancerous patients. Both AST and ALT concentrations are elevated in many hepatic diseases. However, in differentiating cholestatic injury from hepatocellular injury of the liver, aminotransferases are considered useful. Damage in erythrocytes, pancreas, heart and kidney cells are related to activity of AST.

In euthyroid patients, the thyroid gland is removed (thyroidectomy) but the thyroid hormones remain normal from administration of drugs to the patients. T4 and T3 can be measured as free thyroxine (FT4) and free triiodothyronine (FT3), which are indicators of thyroxine and triiodothyronine activities in the body. They can also be measured as total thyroxine and total triiodothyronine, which also depend on the thyroxine and triiodothyronine that are bound to thyroxinebinding globulin. A related parameter is the free thyroxine index, which is total thyroxine multiplied by thyroid hormone uptake which, in turn, is a measure of the unbound thyroxine-binding globulins. Normal levels of thyroid hormones are achieved by giving thyroxine according to the thyroid function test (TFT) levels, which control the normal body mechanism. In this study, we followed the trend and values of TSH, T3, and T4; they were considered not significant as they were in normal ranges.

Thyroxine therapy is withdrawn sometimes in patients to perform radioactive whole body scan (WBS). This allows checking if any remnants of cancerous tissue are left; if so, they are eliminated by radioactive iodine (1131). Moreover, Rosen and his colleagues proposed that risk of osteoporosis and accelerated bone loss are higher in those patients who take suppressive doses of T4 (Rosen, 1998). In this case study, many self-complaints of patients were noted that were related to cramps and pain in body, especially legs. Serum calcium and vitamin D levels were found to be abnormal in those patients.

Estrogen was significantly higher than that in diseased males or control subjects. It is assumed that females have a higher ratio of thyroid tumors than males. Epidemiological studies have proposed that the pathogenesis of thyroid tumors may be associated with the use of estrogens. Manole and his group proposed that females had a 3-fold higher incidence of thyroid tumours than that of males (Manole et al., 2001). Expression levels of estrogen receptor $\alpha$ in males and females are almost same, but in response to $17 \beta$-estradiol, there is a significant 
increase in estrogen receptor $\alpha$ expression levels. $17 \beta$-estradiol stimulates benign and malignant thyroid cells which can result in enhanced expression of cyclin D1 protein and increased cellular proliferation, which play vital roles in the regulation of the G1/S transition of the cell cycle.

Health biomarkers are a good source for detecting any changes or damage occurring in body. This case study included five health biomarkers, namely Homocysteine, Total Oxidant Status (TOS), Malondialdehyde (MDA), Total Antioxidant Response (TAR) and DNA damage. These markers may provide insight into whether thyroid cancer is associated with an oxidant/antioxidant imbalance. A positive relationship of TOS was found with random blood sugars, total proteins, albumin, cholesterol, LDL, TSH, T4, estrogen and MDA.

Homocysteine is significantly higher $(p<0.0001)$ in hypothyroidism conditions of patients. During short term iatrogenic hypothyroidism, Lien et al. found a significant increase in both plasma total homocysteine (tHcy) and serum cholesterol, as well as changes in renal function which are probably explained by the tHcy response (Lien et al., 2000). Moreover, in hypothyroid patients the risk of cardiovascular diseases is increased by the increase of both plasma tHcy and serum cholesterol. In the present study, a positive relationship of homocysteine was established with hemoglobin, erythrocyte sedimentation rate, glycosylated hemoglobin, ALT, FT3, FT4, and DNA damage. In thyroid cancer patients, it was observed that TOS and DNA damage were significantly higher than normal hormone levels.

In the thyroid, pathological and physiological processes in the glands are associated with reactive ROS and free radicals. Oxidative stress can be triggered by imbalance between the production and degradation of ROS, which can lead to damage of different cell components, such as DNA, lipids and proteins. During utilization of $\mathrm{H}_{2} \mathrm{O}_{2}$ in thyroid tissues, oxidative stress is common for thyroxin synthesis, ROS production by inflammation, and when tumor cells undergo active proliferation (FUJITA, 2002).

Our results show that BMI, hemoglobin, random blood sugar, albumin, triglycerides, HDL, LDL, ALT, AST, TSH, homocysteine, MDA and TOS have a positive correlation with DNA damage. From the evidence in literature, the activity of specific oncogenes and the development of neoplastic transformation (by in vivo and in vitro means) involves free radicals in the initiation mechanism. Many published studies have stated that agents that have the ability to remove free radicals or interfere with the activities of free radicals can also have the potential to trigger downstream neoplastic mechanisms at the cellular level as well as molecular level (Sadani, G.R., 1996).

In our study, MDA were non-significantly high in all patients. Studies in the literature explain that in post thyroidectomy, serum MDA levels significantly 
decrease compared to prethyroidectomy levels but are still significantly higher than the control group's level (Akinci et al., 2008). Systemic oxidant/antioxidant status can be better understood or indicated by various levels of MDA or serum enzyme activities. However, these levels cannot indicate real changes occurring in the thyroid directly because many factors are involved to modify serum outcome.

Total antioxidant response (TAR) is also not very significant in this case study. This is because there was not much increase in lipid per-oxidation and damage to the antioxidant defense system. In the prevention of cancer and oxidative stress-related diseases, there are many natural antioxidant agents that have been found to be involved; these include vitamin A (retinoids), carotenoids, selenium, vitamin $E$ (tocopherols), and vitamin $C$ (ascorbic acid). $\beta$-carotene and retinoids have the ability to act as anticarcinogentic agents by antagonizing the biological effects of pro-oxidants on protein kinase C (Carter and Kane, 2004).

Nevertheless, DNA damage and apoptotic responses are not found linked with p73 (protein of thyroid cancer cells). Notably, cell cycle can be arrested by overexpression of p73 in thyroid cancer cells but p73 is unable to induce cell death. Loss of biological function of P73 in neoplastic thyroid cells can be explained by its interaction with mutant p53 and variants of p73 (DeltaNp73) (Taccaliti and Boscaro, 2009). It has been suggested that the development of thyroid malignancies may involve functionally disturbed p73 which may serve as a therapeutic target for thyroid cancer (Frasca et al., 2003). Other oncogenes are Ras proteins, Braf proteins, Trk, RET/PTC, Galectin3, RREB1, TPO, PPFP and $\beta$ catenin; if mutations occur in these oncogenes it could lead to thyroid carcinoma. As indicated in the pathway, another tumor suppressor gene is p53 (a nuclear protein); if mutated, it could lead to thyroid cancer. The increased incidence of poorly differentiated and anaplastic carcinomas, but not welldifferentiated tumors, seem to be related to mutations in p53 and $\beta$-catenin; this may suggest direct molecular triggering of tumor dedifferentiation (Nikiforov, 2004).

\section{Conclusion}

Among endocrine malignancies, thyroid cancer is perhaps the most prevalent. Indeed, thyroid cancer has a high incidence and is the predominant endocrine cancer. The results of the present study suggest there is a notable increase in MDA and DNA damage in thyroid carcinoma patients. In contrast, healthy individuals showed increased levels of HDL-C and TAS. It is suggested that these parameters play pivotal roles in the diagnostic process of determining thyroid carcinoma in patients. Oxidized products of macromolecules in the blood of such patients impart major function in causing thyroid carcinoma disease. 


\author{
Abbreviations \\ ALT: Alanine aminotransaminase \\ ANOVA: Analysis of variance \\ AST: Aspartate aminotransferase \\ BMI: Body Mass Index \\ MDA: Melanodialdehyde \\ OS: Oxidative stress \\ RNS: Reactive nitrogen species \\ ROS: Reactive oxygen species \\ TAR: Total antioxidant response \\ tHcy: Total homocysteine \\ WBS: Whole body scan
}

\title{
Acknowledgements
}

This work was supported by Higher Education Commission under aid to the Universities Programme and Government College University, Faisalabad (GCUF), Government of the Punjab, Pakistan.

\section{Author Contribution}

MU \& SB performed the experimental work and collect the data. MIR supervised and designed the study and contributed to the analysis of the data, AH, ZI, FH, SF, QAA, edited the first draft. LK contributed to the analysis and interpretation of the data \& revised the manuscript. All authors reviewed and commented the final draft.

\section{References}

Abdulmughni, Y. A., Al-Hureibi, M. A., Al-Hureibi, K. A., Ghafoor, M. A., Al-Wadan, A. H., \& Al-Hureibi, Y. A. (2004). Thyroid cancer in Yemen. Saudi Medical Journal, 25(1), 55-59. PMID:14758381

Akinci, M., Kosova, F., Çetin, B., Sepici, A., Altan, N., Aslan, S., \& Çetin, A. (2008). Oxidant/antioxidant balance in patients with thyroid cancer. Acta Cirurgica Brasileira, 23(6), 551-554. https://doi.org/10.1590/S0102-86502008000600013 PMID:19030755

BENJAMIN, M. M. (1978). Outline of veterinary clinical pathology. Ames, lowa State University Press.

Carter, C. A., \& Kane, C. J. (2004). Therapeutic potential of natural compounds that regulate the activity of protein kinase C. Current Medicinal Chemistry, 11(21), 28832902. https://doi.org/10.2174/0929867043364090 PMID:15544481

Duncan, D. B. (1955). Multiple Range and Multiple F Tests. Biometrics, 11(1), 1. https:// doi.org/10.2307/3001478 
Erel, O. (2004). A novel automated method to measure total antioxidant response against potent free radical reactions. Clinical Biochemistry, 37(2), 112-119. https:// doi.org/10.1016/j.clinbiochem.2003.10.014 PMID:14725941

Erel, O. (2005). A new automated colorimetric method for measuring total oxidant status. Clinical Biochemistry, 38(12), 1103-1111. https://doi.org/10.1016/j.clinbiochem. 2005.08.008 PMID:16214125

Finkel, T. (2003). Oxidant signals and oxidative stress. Current Opinion in Cell Biology, 15(2), 247-254. https://doi.org/10.1016/S0955-0674(03)00002-4 PMID:12648682

Frasca, F., Vella, V., Aloisi, A., Mandarino, A., Mazzon, E., Vigneri, R., \& Vigneri, P. (2003). p73 tumor-suppressor activity is impaired in human thyroid cancer. Cancer Research, 63(18), 5829-5837. PMID:14522906

Fujita, T. (2002). [Formation and removal of reactive oxygen species, lipid peroxides and free radicals, and their biological effects]. Yakugaku Zasshi, 122(3), 203-218. https://doi.org/10.1248/yakushi.122.203 PMID:11905046

Jackson, A. L., \& Loeb, L. A. (2001). The contribution of endogenous sources of DNA damage to the multiple mutations in cancer. Mutation Research. Fundamental and Molecular Mechanisms of Mutagenesis, 477(1-2), 7-21. https://doi.org/10.1016/ S0027-5107(01)00091-4 PMID:11376682

Karbownik, M., \& Lewinski, A. (2003). The role of oxidative stress in physiological and pathological processes in the thyroid gland; possible involvement in pineal-thyroid interactions. Neuroendocrinology Letters, 24(5), 293-303. PMID:14647000

Kitahara, C. M., Platz, E. A., Freeman, L. E. B., Hsing, A. W., Linet, M. S., Park, Y., . . Berrington de González, A. (2011). Obesity and thyroid cancer risk among U.S. men and women: A pooled analysis of five prospective studies. Cancer Epidemiology, Biomarkers \& Prevention, 20(3), 464-472. https://doi.org/ 10.1158/1055-9965.EPI-10-1220 PMID:21266520

Le Bras, M., Clément, M. V., Pervaiz, S., \& Brenner, C. (2005). Reactive oxygen species and the mitochondrial signaling pathway of cell death. Histology and Histopathology, 20(1), 205-219. PMID:15578439

Lien, E. A., Nedrebø, B. G., Varhaug, J. E., Nygård, O., Aakvaag, A., \& Ueland, P. M. (2000). Plasma total homocysteine levels during short-term iatrogenic hypothyroidism. The Journal of Clinical Endocrinology and Metabolism, 85(3), 1049-1053. https:// doi.org/10.1210/jcem.85.3.6439 PMID:10720038

Mancini, A., Segni, C. Di, Raimondo, S., Olivieri, G., Silvestrini, A., Meucci, E. and Currò, D. (2016) 'Thyroid Hormones, Oxidative Stress, and Inflammation', 2016. https:// doi.org/10.1155/2016/6757154

Manole, D., Schildknecht, B., Gosnell, B., Adams, E., \& Derwahl, M. (2001). Estrogen promotes growth of human thyroid tumor cells by different molecular mechanisms. The Journal of Clinical Endocrinology and Metabolism, 86(3), 1072-1077. https://doi.org/ 10.1210/jcem.86.3.7283 PMID:11238488

Mulaudzi, T. V., Ramdial, P. K., Madiba, T. E., \& Callaghan, R. A. (2001). Thyroid carcinoma at King Edward VIII Hospital, Durban, South Africa. East African Medical Journal, 78(5), 242-245. https://doi.org/10.4314/eamj.v78i5.9046 PMID:12002083

Nikiforov, Y. E. (2004). Genetic alterations involved in the transition from welldifferentiated to poorly differentiated and anaplastic thyroid carcinomas. Endocrine Pathology, 15(4), 319-327. https://doi.org/10.1385/EP:15:4:319 PMID:15681856 
Rosen, H. N., Moses, A. C., Garber, J., Ross, D. S., Lee, S. L., Ferguson, L., . . Greenspan, S. L. (1998). Randomized trial of pamidronate in patients with thyroid cancer: Bone density is not reduced by suppressive doses of thyroxine, but is increased by cyclic intravenous pamidronate. The Journal of Clinical Endocrinology and Metabolism, 83(7), 2324-2330. https://doi.org/10.1210/jc.83.7.2324 PMID:9661603

Sadani, G. R., \& Nadkarni, G. D. (1996). Role of tissue antioxidant defence in thyroid cancers. Cancer Letters, 109(1-2), 231-235. https://doi.org/10.1016/ S0304-3835(96)04484-9 PMID:9020926

Siti, H. N., Kamisah, Y., \& Kamsiah, J. (2015). The role of oxidative stress, antioxidants and vascular inflammation in cardiovascular disease (a review). Vascular Pharmacology, 71, 40-56. https://doi.org/10.1016/j.vph.2015.03.005 PMID:25869516

Steel, Robert GD, James H. Torrie, and David A. Dickey (1997). Principles and procedures of statistics: A biological approach. New York: McGraw-Hill, cop.

Taccaliti A, Boscaro M. (2009). Genetic mutations in thyroid carcinoma. Minerva Endocrinol 34:11-28.

Valko, M., Leibfritz, D., Moncol, J., Cronin, M. T., Mazur, M., \& Telser, J. (2007). Free radicals and antioxidants in normal physiological functions and human disease. The International Journal of Biochemistry \& Cell Biology, 39(1), 44-84. https://doi.org/ 10.1016/j.biocel.2006.07.001 PMID:16978905

Weg, S. B. (no date). Spectrophotometer simpler to use and higher in dependability thanks to mounting of a large-size color LCD. 